\title{
Concentration Profiles of Regulated and Unregulated Pollutants Emitted from the Combustion of Soybean Biodiesel and Diesel/Biodiesel Blend Originating of a Diesel Cycle Engine
}

\author{
Beatriz S. Amaral, ${ }^{a, b}$ Luciana M. B. Ventura, ${ }^{a}$ Ariane S. Amaral, ${ }^{c}$ Francisco R. A. Neto ${ }^{c}$ \\ and Adriana Gioda ${ }^{*, a}$ \\ ${ }^{a}$ Departamento de Química, Pontifícia Universidade Católica do Rio de Janeiro (PUC-Rio), \\ 22451-900 Rio de Janeiro-RJ, Brazil \\ ${ }^{b}$ Instituto Federal do Rio de Janeiro (IFRJ), 20270-020 Rio de Janeiro-RJ, Brazil \\ 'Instituto de Química, LADETEC, Universidade Federal do Rio de Janeiro (UFRJ), \\ 21941-598 Rio de Janeiro-RJ, Brazil
}

\begin{abstract}
This study evaluated the concentration profiles of regulated and unregulated pollutants emitted from a stationary diesel engine cycle, operating at the speed of $1800 \mathrm{rpm}$ and $0 \%$ load, using biofuels and binary blends. The experimental test considered fuel burning time on three different periods and storage times. The operation of the engine when it is still cold, for example at 15 minutes, showed negative effect on particulate matter (PM), benzene and ethylbenzene emissions in pure soybean biodiesel (B100) compared to the blend of diesel with 5\% biodiesel (B5). Regarding to the concentration of mono aromatics, aliphatic hydrocarbons and polycyclic aromatic hydrocarbons (PAH), this study showed similar results to those reported in the literature, where B5 fuel emits more pollutants than pure biodiesel. However, comparing some pollutants individually, benzene and ethylbenzene emissions were higher for B100 and pure soybean biodiesel with butil-hydroxyanisol additive (B100 Adt). The B5 showed the highest concentration profile for the PAH sum in the gaseous and particulate phases in longer engine operation periods.
\end{abstract}

Keywords: vehicular emission, biofuels, BTEX, particulate matter, PAH

\section{Introduction}

Energy has been the basis for the development of the civilizations and its demand has increased significantly throughout History. Currently, the main type of energy consumed in the world is originated from nonrenewable sources, from which many pollutants can be generated. Therefore, the current challenge aims to reduce impacts caused by global warming and the search for alternative energy sources. ${ }^{1}$

In academic and political centers, discussions involving the topics "air quality" and "pollution sources" draw particular attention in the effort to reverse the critical degradation of air quality caused by the socioeconomic development in recent decades. ${ }^{2}$ Thus, it already seems to be a global consensus the need for the improvement and efficient distribution of preventive and corrective measures.

*e-mail: agioda@puc-rio.br
Several factors threaten air quality. Among them, are the emissions originated from vehicles, which directly and indirectly affect the composition of the air, resulting in damages to the flora, fauna and human health. ${ }^{3}$

There is a global tendency to reduce the use of petroleum-derived fuels and thus it increases the demand for a fuel renewable. The bioenergy commercialization created an efficient way to solve the problem of petroleum shortage and its negative influence on the environment. ${ }^{4}$

Biodiesel is a biodegradable fuel produced from renewable sources, to full or partially replace fossil fuels. Despite having many advantages, this biofuel has some properties that need improvement, such as, higher density, surface tension, viscosity and lower power. ${ }^{5}$ These characteristics can influence the combustion processes and hence the pollutant emissions. Other factors that cannot be neglected to evaluate the effects of biodiesel pollutant emissions are engine characteristics, operation conditions and the biofuels synthesis route. ${ }^{6}$ 
In the literature, it is known that various authors reported emission decrease of particulate matter using biofuels. ${ }^{7-9}$ Though a small number of authors do not find any significant difference between diesel (B0) and pure biodiesel (B100) and there are others that have found smaller emissions for diesel than biodiesel..$^{10-12}$

On the other hand, studies about pollutant emissions reduction for oxidized biofuels or mixed ones are scarce. Monyem and Van Gerpen ${ }^{13}$ noted that oxidized biodiesel emitted less carbon monoxide and hydrocarbons than unoxidized biodiesel. Bakeas et al..$^{14}$ observed increases in emissions of polycyclic aromatic hydrocarbons (PAH) from motor working with binary mixtures of diesel and biodiesel oxidized and attributed this increase to the fuel quality. Based on these results, there is still much to be studied and evaluated. ${ }^{15}$

Particulate matter (PM) concentrations can be influenced by soluble organic fraction (SOF) because high amount of unburned fuel coming out of the engine exhaust. A study conducted in $2011^{16}$ found that in a condition of no load, SOF was higher for B100 than for diesel. In this case, the particles consisted of an organic product, mainly benzene and soot.

Organic compounds, such as benzene, toluene, ethylbenzene, $o$-xylene, $m$-xylene and $p$-xylene (BTEX) have been identified as carcinogens and mutagens. ${ }^{9}$ In general, the emissions of BTEX decreased with the increase of biodiesel content in the diesel/biodiesel blend because aromatics are virtually absent in biofuel. However, some studies showed that the profiles of vehicle emissions of these pollutants are influenced by engine operation conditions (i.e., load, speed, and ignition temperature), quality and type of fuel. ${ }^{15,17,18}$

PAH have been subject of great interest due to its health risks. The emissions impact of these compounds using biodiesel are also questioned in the literature and the reports are not very consistent. ${ }^{15}$ Several authors have reported PAH reductions with the use of biofuel, but these findings are associated to the type and engine operation conditions. ${ }^{15}$

Some authors had not observed significant differences in PAH emissions associated with biodiesel. ${ }^{19}$ However, the particulate $\mathrm{PAH}$ emissions, which have more implications to adverse health effects, were almost unchanged and did not show significant reduction. ${ }^{20}$

A strong trend towards higher PAH emissions was observed with oxidized frying oil biodiesel blends. Diesel containing 30,50, and $80 \%$ biodiesel presented higher PAH content of 15,21 , and $40 \%$, respectively, than pure diesel. ${ }^{14}$

To establish new air quality standards based on a renewable energy matrix, as in the case of biodiesel, it is essential to know the gases, volatiles and the particle concentration levels emitted by combustion processes of vehicular engines, as well as their chemical compositions. Several countries have environmental legislation for emission control of certain pollutants, the so-called regulated pollutants, such as carbon monoxide (CO), particulate matter $(\mathrm{PM})$, nitrogen oxides $\left(\mathrm{NO}_{\mathrm{x}}\right)$, ozone $\left(\mathrm{O}_{3}\right)$, and total hydrocarbons (HCT). However, some authors included in their research unregulated pollutants, such as aldehydes, BTEX, and PAH. ${ }^{5,6}$

This study presents the concentration profiles of regulated (PM) and unregulated pollutants (BTEX, aliphatic hydrocarbons, PAH, aldehydes and metals) associated to emissions of a diesel cycle engine used in stationary mode. The engine worked with biofuels: pure soybean biodiesel (B100), soybean biodiesel additivated with butyl-hydroxyanisole (B100 Adt) and a binary mixture of fossil diesel with 5\% biodiesel (commercial diesel, B5). The concentration profiles were compared before and after the accelerated oxidation process of the fuel during storage in an oven at $40{ }^{\circ} \mathrm{C}$ at different periods.

\section{Experimental}

\section{Sampling}

Pure soybean biodiesel (B100) and soybean biodiesel with butyl-hydroxyanisol (BHT) additive (B100 Adt) were provided by the Strategic Technologies Center of the Northeast (CETENE), in the Pernambuco State, Brazil. Commercial diesel, i.e., fossil diesel 95 and $5 \%$ biodiesel (B5), was collected at fuel distribution stations in the João Pessoa city, Paraiba State, Brazil.

The emissions of fuels B5, B100, and B100 Adt were evaluated regarding to the oxidation processes. Therefore, the fuels were stored in an oven at $40^{\circ} \mathrm{C}$ for different periods (T1: seven days; T2: fourteen days; and T3: twenty-one days). This study was carried out in the Northeast region of Brazil where $40{ }^{\circ} \mathrm{C}$ is an easily reached temperature, especially in summer. These emissions were collected with a sampling time of 30 minutes. The samples not stored in an oven were labeled as $\mathrm{T} 0$. The emissions were evaluated during engine operation period in the sampling times of 15,30 , and 60 minutes referred as B100/15, B100 Adt/15, B5/15, B100/30, B100 Adt/30, B5/30, B100/60, B100 Adt/60 and B5/60.

The combustion products were originated from a stationary engine of the diesel cycle: with a single-cylinder of $10 \mathrm{HP}$ coupled to a generator (Toyama, T6000 CXE3 Model, São Paulo, Brazil), with speed of 1800 rpm, 0\% load, and $60 \mathrm{~Hz}$. 
The sampling system is an acrylic chamber with $8.0 \mathrm{~mm}$ of thickness and measuring approximately $1 \mathrm{~m}^{3}$. This box is transparent with a mobile lid for easy handling of samples. The chamber was designed with holes at the top (lid), to insert sensors, filters and cartridges, and in the lower side, for emissions entry from the engine. The connection between the motor and the chamber was made with PVC pipe (Figure 1). The chamber was designed to collect emissions without contamination of the external environment and not dilute samples. The sampling system also contained a "manifold" (glass tube with four side outlets) vacuum pump for air suction, flowmeters, sensors (temperature and humidity), filters, and cartridges for samples. The filters and cartridges were connected to a vacuum pump by silicone tubes and connected to flowmeters. ${ }^{21}$ The sensors performed measures in real time during the burning fuel. All samples were collected under the same engine operation conditions, in triplicates.

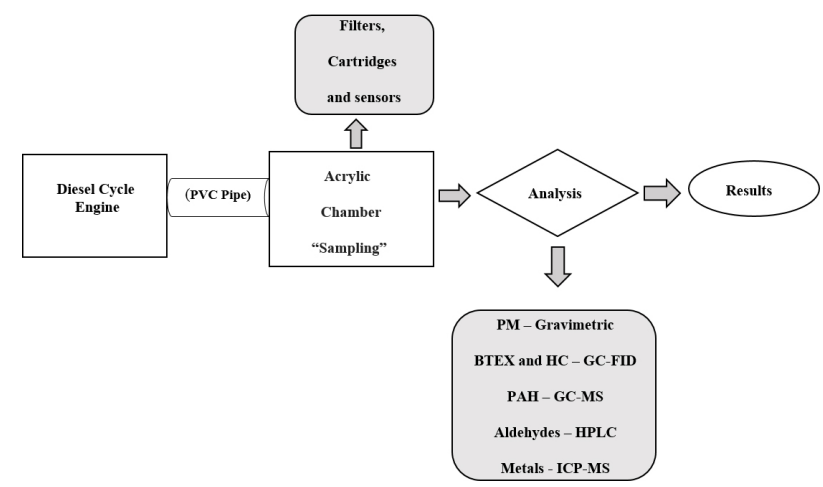

Figure 1. Scheme of determination of regulated and unregulated pollutants emitted by a diesel cycle engine fueled with B100, B100 Adt, and B5.

Particulate matter samples were collected in polycarbonate filters of $0.4 \mu \mathrm{m}$ pore and $37 \mathrm{~mm}$ diameter (Millipore, Model 03700 HTTP, Belford, MA, USA) with a flow rate of $10 \mathrm{~L} \mathrm{~min}^{-1}$. Organic compounds were sampled in specific cartridges for each analyte. Activated charcoal cartridges (SKC Inc., cat. No. 226-01, Eighty Four, PA, EUA) were used to collect BTEX and XAD-2 (SKC Inc., cat. No. 226-30-06, Eighty Four, PA, EUA) for aliphatic hydrocarbons and gaseous PAH. For aldehydes, cartridges impregnated with 2,4-dinitrophenylhydrazine solution (DNPH) (SKC Inc., cat. No. 226-119, Eighty Four, PA, EUA) were used. For all gaseous compounds the flow rate was $1.0 \mathrm{~L} \mathrm{~min}^{-1} .21$

\section{Chemical analysis}

Particulate matter was determined by gravimetric analysis. Filters containing PM were conditioned in a desiccator with $80 \%$ glycerol solution $(\mathrm{v} / \mathrm{v})$ for at least
24 hours. They were weighed before and after sampling in an analytical balance (Mettler Toledo, Model 205 XP, Barueri, SP, Brazil), with $0.00001 \mathrm{~g}$ accuracy. ${ }^{21}$

For desorption of the analytes, the activated charcoal cartridges and XAD-2 containing the adsorbent material were broken at the ends with the aid of suitable pliers and the adsorbent was transferred to a $2.0 \mathrm{~mL}$ glass vial properly identified. To avoid losses, the vials were immediately sealed and placed in an ice bath. The volume of $1.5 \mathrm{~mL}$ of dichloromethane $99.9 \%$ (Tedia, Rio de Janeiro, RJ, Brazil) was slowly added in an ice bath with the aid of a $2.0 \mathrm{~mL}$ syringe.

BTEX were determined by gas chromatography with flame ionization detection (GC-FID) (Agilent Technologies, Model Hewlett-Packard 7890, Series II, Palo Alto, CA, USA). The separation of the analytes were performed using an Innowax column $(25 \mathrm{~m} \times 0.2 \mathrm{~mm} \times 0.4 \mu \mathrm{m} \mathrm{df})$ with injector and detector temperatures at $250{ }^{\circ} \mathrm{C}$. A heating ramp was programmed with a temperature of $40{ }^{\circ} \mathrm{C}$ : $4{ }^{\circ} \mathrm{C} \mathrm{min}^{-1}$ up to $53{ }^{\circ} \mathrm{C} ; 40^{\circ} \mathrm{C} \mathrm{min}^{-1}$ up to $200^{\circ} \mathrm{C}$. The carrier gas was $\mathrm{H}_{2}$ and the injection volume $1.0 \mu \mathrm{L}$. The standard solutions were prepared from standard mixtures of benzene, toluene, ethylbenzene, and xylenes with concentration of $2000 \mathrm{mg} \mathrm{L}^{-1}$ per analyte (Sigma-Aldrich, São Paulo, SP, Brazil). The concentrations of the analytical curve varied from 1.0 to $100.0 \mu \mathrm{g} \mathrm{mL}^{-1}{ }^{18}$

The aliphatic hydrocarbons ( $\mathrm{n}-\mathrm{C} 10$ to $\mathrm{n}-\mathrm{C} 30)$ were determined by GC-FID (Agilent Technologies, Model Hewlett-Packard 5890, Series II, Palo Alto, CA, USA). To separate the analytes, a HP-VOC column, $100 \%$ methylpolysiloxane $(60 \mathrm{~m} \times 0.2 \mathrm{~mm} \times 1.12 \mu \mathrm{m} \mathrm{df})$ was used with an injector temperature of $260{ }^{\circ} \mathrm{C}$ and detector at $290{ }^{\circ} \mathrm{C}$. A heating ramp was programmed with a starting temperature of $40{ }^{\circ} \mathrm{C}: 3{ }^{\circ} \mathrm{C} \mathrm{min}^{-1}$ up to $280{ }^{\circ} \mathrm{C}$. The carrier gas was $\mathrm{H}_{2}$ and the injection volume $1.0 \mu \mathrm{L}$. The standard solutions were prepared from a mixture of hydrocarbons n-C10 to n-C30 (TRPH Standard, Lot No.: CG2870 $500 \pm 2.5 \mu \mathrm{g} \mathrm{mL}{ }^{-1}$, Tedia, Rio de Janeiro, RJ, Brazil). The internal standard was a deuterated toluene solution D8 (99.6\% Tedia, Rio de Janeiro, RJ, Brazil) prepared at a concentration of $100 \mu \mathrm{g} \mathrm{mL}^{-1}$. The concentrations of the analytical curve varied from 10.0 to $200.0 \mu \mathrm{g} \mathrm{mL}{ }^{-1} .^{22}$

The aldehydes were determined by high-performance liquid chromatography (HPLC, Agilent Technologies, model 1100 Series, Palo Alto, CA, USA) with diode array detector (DAD, G1315B). The chromatographic separation was performed using Zorbax Eclipse XDB column $(4.6 \mathrm{~mm} \times 150 \mathrm{~mm} \times 5 \mu \mathrm{m})$. The standard solution used was a mixture of carbonyl (Supelco, ref. 011 / IP 6A aldehyde/ acetone DNPH). The concentrations of the analytical curve 
varied from 0.012 to $0.6 \mu \mathrm{g} \mathrm{mL} \mathrm{m}^{-1}$. To carry out the extraction of these analytes, the adsorbent material was transferred to an $8.0 \mathrm{~mL}$ glass vial and $5.0 \mathrm{~mL}$ of acetonitrile (HPLC grade Tedia, Rio de Janeiro, RJ, Brazil) was added. Then, the vials were put in an ultrasonic bath for 30 minutes. The mobile phase was water/acetonitrile and the injection volume was $10 \mu \mathrm{L}$. The method for determining formaldehyde and acetaldehyde was adapted from Corrêa and Arbilla. ${ }^{23}$

$\mathrm{PAH}$ associated to the PM, emitted in the gas phase, were determined by gas chromatography coupled to mass spectrometry (GC-MS, MS-Thermo Scientific Model ITQ-Ion Trap; GC: Thermo Finnigan, Model Trace GC). For the determination of the PAH associated to the PM, the filters were extracted with dichloromethane in an ultrasonic bath (UNIQUE, Model USC 1400, Indaiatuba, SP, Brazil), as reported by USEPA (Method 3550B, 1996). ${ }^{22}$ The method for extraction of PAH was adapted from Corrêa and Arbilla. ${ }^{22}$ PAH in the gaseous phase were analyzed from extracts of XAD-2 cartridges, which were also extracted with dichloromethane. The column was a DB5 $(30 \mathrm{~m} \times 0.25 \mathrm{~mm} \times 0.25 \mu \mathrm{m})$ and the injector temperature was $290{ }^{\circ} \mathrm{C}$. The heating ramp was programmed at $50^{\circ} \mathrm{C}$ for 5 minutes; $5^{\circ} \mathrm{C} \mathrm{min}{ }^{-1}$ up to $80^{\circ} \mathrm{C}, 6^{\circ} \mathrm{C} \mathrm{min}^{-1}$ from $80^{\circ} \mathrm{C}$ up to $280^{\circ} \mathrm{C}$ and $280{ }^{\circ} \mathrm{C}$ for 25 minutes. Injection volume was $1.4 \mu \mathrm{L}$ and the carrier gas was He. The equipment was calibrated using a standard mixture containing $16 \mathrm{PAH}$ and deuterated internal standards (naphthalene-D8, acenaphthene-D10, phenanthrene-D10, chrysene-D12, and perylene-D12) with concentrations of $100.0 \mathrm{ng} \mathrm{mL}^{-1}$. The concentrations of the analytical curve varied from 2.0 to $200.0 \mathrm{ng} \mathrm{mL}^{-1}$. The analytical protocol used was based on EPA-8270D method. ${ }^{24}$

Metals associated to the PM and metals in the fuels (B5, B100 and B100 Adt) were analyzed by inductively coupled plasma mass spectrometry (ICP-MS, PerkinElmer/ Sciex, Model Nex Ion 300 X, Norwalk, CT, USA). The operation conditions were: ICP power $1200 \mathrm{~W}$; argon plasma flow rate of $17.00 \mathrm{~L} \mathrm{~min}^{-1}$; argon auxiliary flow rate of $1.1 \mathrm{~L} \mathrm{~min}^{-1}$; argon nebulizer flow rate of $1.02 \mathrm{~L}$ $\mathrm{min}^{-1}$. Filters containing PM were extracted with $3.00 \mathrm{~mL}$ of bidistilled nitric acid, digested for 2 hours at $95{ }^{\circ} \mathrm{C}$ and cooled to $20-25{ }^{\circ} \mathrm{C} .{ }^{25}$ Then, the extracts were centrifuged to separate insoluble particles and diluted with ultrapure water. The metals quantified in the extracts were $\mathrm{Al}, \mathrm{V}$, $\mathrm{Cr}, \mathrm{Mn}, \mathrm{Fe}, \mathrm{Ni}, \mathrm{Cu}, \mathrm{Zn}, \mathrm{Ga}, \mathrm{Cd}, \mathrm{Sb}, \mathrm{Pb}, \mathrm{Ti}, \mathrm{Ba}, \mathrm{Na}, \mathrm{Mg}$, $\mathrm{Ca}, \mathrm{Co}$, and $\mathrm{K}$. Calibration solutions were prepared from multielement standard solutions $1000 \mu \mathrm{g} \mathrm{L}{ }^{-1}$ (PerkinElmer 29 and Merck Titrisol) and acidified with bidistilled nitric acid. The concentrations of the analytical curve varied from 5.0 to $80.0 \mu \mathrm{g} \mathrm{L}^{-1}$ and the internal calibration standard was $\mathrm{Rh}$ in the concentration of $10.0 \mu \mathrm{g} \mathrm{L}^{-1} .25$
For the determination of metals in the fuels, $0.7417 \mathrm{~g}$ of B5, $0.7896 \mathrm{~g}$ of B100 Adt, and $0.7952 \mathrm{~g}$ of B100 were weighed and transferred to Teflon tubes with the addition of $5.0 \mathrm{~mL}$ of bidistilled nitric acid. The flasks were placed in a block digester (DAH-904, Berghof, Germany) with programmed temperature starting at $100{ }^{\circ} \mathrm{C}$ for 30 minutes residence time followed by $10{ }^{\circ} \mathrm{C}$ for 30 minutes up to $160{ }^{\circ} \mathrm{C}$. The flasks were then cooled to room temperature, diluted with ultrapure water to $50 \mathrm{~mL}$ and analyzed by ICP-MS.

\section{Statistical analysis}

In order to verify significant differences in the pollutants concentrations emitted by biofuels (B100 and B100 Adt) and B5, the Student's $t$-test was applied with 95\% confidence level considering: (H0) - there are no significant differences between the mean concentrations of the pollutants emitted; (H1) - there are significant differences between mean concentrations of the pollutants emitted.

\section{Results and Discussion}

\section{Particulate matter}

Higher PM concentrations were observed during the initial minutes of the engine operation, i.e., on the first 15 minutes (Table 1). This increasing of particle emission during the initial stages is probably due to engine being is still cold, therefore not operating in ideal conditions, resulting in an incomplete combustion.

The lowest PM concentrations were observed for B5 in all engine operation times (Table 1). Differences statistically significant were obtained comparing B5/15 vs. B100/15, B100 Adt/60 vs. B5/60 and B100/60 vs. B100 Adt/60 (Tables S1, S2, and S3, Supplementary Information). Another important finding was that oxidation processes reduced particulate emissions for all tested fuel. Overall, B100, which is the evaluated biofuel most susceptible to oxidation, emitted slightly less PM than B100 Adt. The explanation for this behavior may be the presence of more oxygenated compounds in B100 than in B100 Adt that yields more efficient burning. Student's $t$-test showed similarities between PM emissions from B100 vs. B100 Adt, except for B100/60. These results are consistent with studies of Yamane et al. ${ }^{26}$

Application of the Student's $t$-test to the biofuels (B100 and B100 Adt) resulted in significantly different average concentrations, when compared to commercial diesel (B5), for PM emissions in the storage periods T1, T2 and T3 (Tables S1, S2 and S3, Supplementary Information). 
Table 1. PM concentration profiles $\left(\mu \mathrm{g} \mathrm{m}^{-3}\right)$ for B100, B100 Adt and B5 emissions considering the engine operation time (15, 30, and 60 min) and the storage periods (T1, T2, and T3) sampled for 30 minutes

\begin{tabular}{|c|c|c|c|}
\hline & \multicolumn{3}{|c|}{ Fuel (mean \pm standard deviation) } \\
\hline & $\mathrm{B} 100 /\left(\mu \mathrm{g} \mathrm{m}^{-3}\right)$ & $\mathrm{B} 100 \mathrm{Adt} /\left(\mu \mathrm{g} \mathrm{m}^{-3}\right)$ & $\mathrm{B} 5 /\left(\mu \mathrm{g} \mathrm{m}^{-3}\right)$ \\
\hline \multicolumn{4}{|c|}{ Engine operation time / min } \\
\hline 15 & $9104 \pm 1056$ & $6309 \pm 1848$ & $4252 \pm 278$ \\
\hline 30 & $3515 \pm 838$ & $4256 \pm 729$ & $3237 \pm 511$ \\
\hline 60 & $2945 \pm 27$ & $4087 \pm 206$ & $2759 \pm 101$ \\
\hline \multicolumn{4}{|c|}{ Storage periods } \\
\hline $\mathrm{T} 1$ & $4970 \pm 224$ & $4381 \pm 1052$ & $2466 \pm 258$ \\
\hline $\mathrm{T} 2$ & $3068 \pm 359$ & $3574 \pm 515$ & $2143 \pm 385$ \\
\hline $\mathrm{T} 3$ & $3103 \pm 410$ & $3544 \pm 23$ & $1785 \pm 344$ \\
\hline
\end{tabular}

Several studies observed significant reductions in PM emissions comparing biodiesel binary blends to fossil diesel. Nevertheless, all of them reported that the operation conditions and engine characteristics should be considered for comparison of biofuels vehicle emissions. ${ }^{15-17}$

\section{BTEX}

The fuels presented different emission profiles for BTEX (Figure 2). At 15 minutes of engine operation, B100 and B100 Adt emitted more benzene and ethylbenzene and less toluene compared to B5. The results of the Student's $t$-test showed that emissions of benzene, toluene, and ethylbenzene from B100 and B100 Adt were not statistically different. These results were consistent for all sampling and storage times (Table S1, Supplementary Information). The characteristics of the vehicle emissions of these pollutants are influenced by engine operational conditions (load, speed, and ignition temperature), quality and type of fuel. ${ }^{17,18}$ Previous studies showed that benzene emission is proportional to the addition of biodiesel in the fuel. Turrio-Baldassarri et al. ${ }^{27}$ reported benzene emissions of $4.2 \mathrm{mg} \mathrm{kW}^{-1} \mathrm{~h}^{-1}$ for diesel and $6.8 \mathrm{mg} \mathrm{kW}^{-1} \mathrm{~h}^{-1}$ for B20. These results are in agreement with this study in which benzene emissions were slightly higher in B100 than in B5 in 15 and 60 minutes.

The results of BTEX emissions can be expressed as a ratio between aromatic compounds. In this study the ratios of xylenes/ethylbenzene for B5 ranged from 1.73 to 2.02 for the stored fuel and 1.33 and 0.91 for B5/30 and $\mathrm{B} 5 / 60$, respectively. The ratios found for the stored fuel are similar to those found around a petrochemical complex in two regions of São Paulo State (2.2 and 1.8). ${ }^{28}$ The ratios benzene/ethylbenzene São Paulo State. These results are consistent with those found in the literature for binary blends of diesel/biodiesel, 1.88, ${ }^{22} 2.47^{27}$ and 1.29. ${ }^{17}$

Studies showed that in general, regardless of biodiesel source, BTEX emissions of binary blends burning decrease compared to fossil diesel. ${ }^{9}$ Similar results were observed in this study for emission of these pollutants and B5 emitted all the compounds. Previous studies showed that benzene emissions were higher for B100, while toluene emissions associated with diesel the engine operational conditions (Table 2). These profiles are similar to those found in this study.

\section{Aliphatic hydrocarbons}

The results found for the aliphatic hydrocarbons in this study are in agreement with the results reported in literature, where $n$-alkanes originated from fossil fuels present $\mathrm{n}-\mathrm{C}<23$. At high temperatures, the $n$-alkanes with lower carbon number are present in the gaseous phase and they are associated to PM. ${ }^{30}$ As expected, emission of these pollutants only occurred when the engine was powered with $\mathrm{B} 5$, as the fraction of fossil diesel is composed primarily by hydrocarbons (HC). Overall, studies show that regardless of biodiesel origin, $\mathrm{HC}$ emissions originated from the combustion of either B100 or binary blends decrease compared to pure diesel. ${ }^{4,31,32}$ It can be explained by the higher oxygen content in the molecule, resulting in more available oxygen which contributes to a better combustion. Moreover, the emissions of $\mathrm{HC}$ can be influenced by the load engine conditions. ${ }^{33}$ At high loads, there is an increase in emissions of these pollutants because the availability of oxygen decreases. In this study, biofuels were tested in an engine with no load, due to a greater availability of oxygen resulting in a lower emission of aliphatic $\mathrm{HC}$.

\section{Polycyclic aromatic hydrocarbons}

The main PAH compounds found in the emissions for all fuels, samplings, and storage times were naphthalene (NAF), acenaphthylene (ACY), fluorene (FLU), phenanthrene (PHE), fluoranthene (FLU), and pyrene (PYR). In the gaseous phase, the most abundant were NAF 


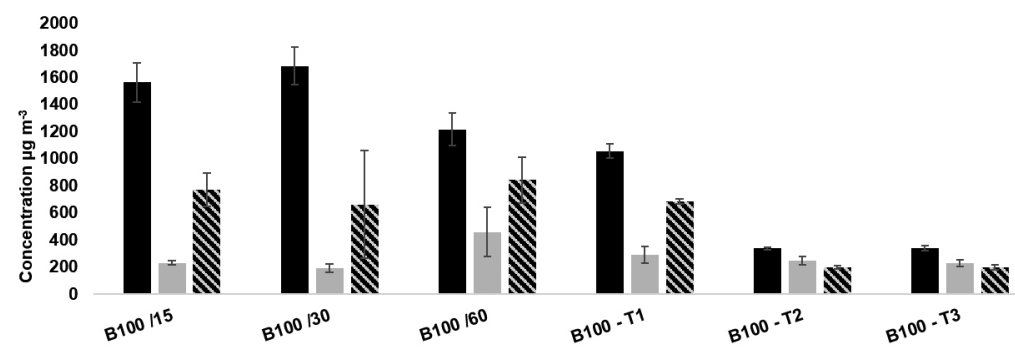

(a) -Benzene $\quad$ Toluene sethylbenzene

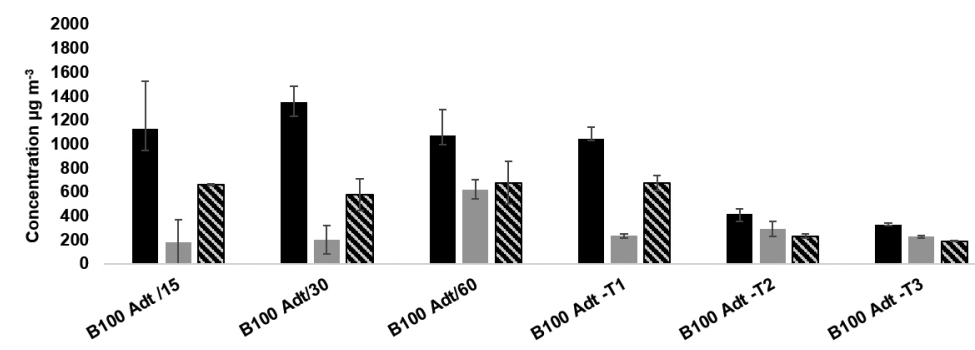

(b) Benzene $\square$ Toluene vethylbenzene

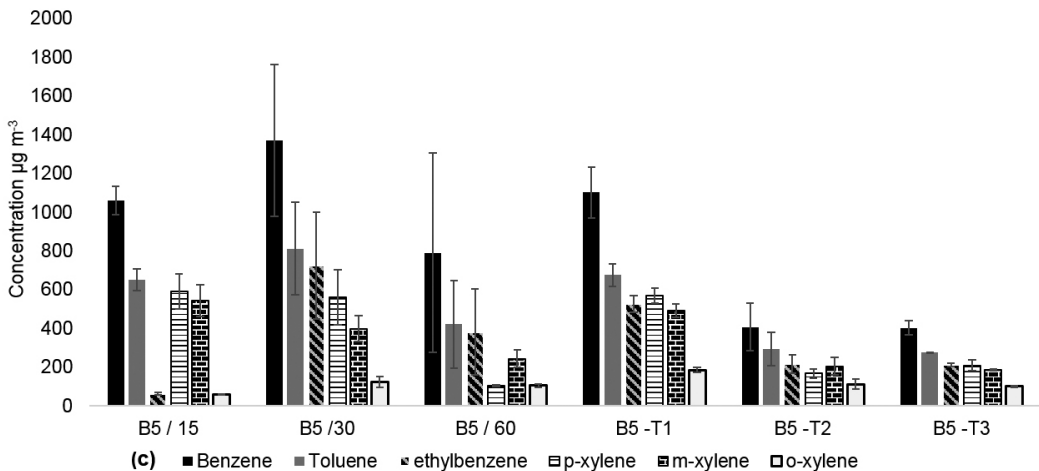

Figure 2. Mean concentration profile $\left(\mu \mathrm{g} \mathrm{m}^{-3}\right)$ of BTEX for: (a) B100; (b) B100 Adt; (c) B5. Operation time of the engine was 15, 30, and 60 minutes, and storage periods of $\mathrm{T} 1, \mathrm{~T} 2$, and $\mathrm{T} 3$ sampled for 30 minutes.

Table 2. Results of previous studies for emissions of PM, benzene, and toluene originated by diesel cycle engine fueled with diesel, biodiesel, and binary mixtures

\begin{tabular}{|c|c|c|c|c|c|}
\hline Engine type & $\begin{array}{c}\text { Operating conditions } \\
\text { (speed / load) }\end{array}$ & Fuel & $\begin{array}{c}\mathrm{PM} / \\
\left(\mathrm{mg} \mathrm{m}^{-3}\right)\end{array}$ & $\begin{array}{c}\text { Benzene / } \\
\left(\mathrm{mg} \mathrm{kW}^{-1} \mathrm{~h}^{-1}\right)\end{array}$ & $\begin{array}{c}\text { Toluene / } \\
\left(\mathrm{mg} \mathrm{kW}^{-1} \mathrm{~h}^{-1}\right)\end{array}$ \\
\hline \multirow{6}{*}{$\begin{array}{l}\text { Generator has } \\
\text { a diesel engine } \\
\text { (without catalyst } \\
\text { installation) } \\
\text { (NM260L } \\
\text { Mitsubishi) }\end{array}$} & \multirow{3}{*}{ no load } & diesel & 71.5 & - & - \\
\hline & & B10 (soy-biodiesel blends) & 61.7 & - & - \\
\hline & & B50 (soy-biodiesel blends) & 81.3 & - & - \\
\hline & \multirow{3}{*}{$10 \mathrm{~kW}$} & diesel & 96.0 & - & - \\
\hline & & B10 (soy-biodiesel blends) & 95.3 & - & - \\
\hline & & B50 (soy-biodiesel blends) & 177 & - & - \\
\hline \multirow{4}{*}{$\begin{array}{l}\text { Bench engine with } \\
\text { direct injection }{ }^{17}\end{array}$} & \multirow{2}{*}{$500 \mathrm{~W}$} & diesel & 838 & - & - \\
\hline & & B100 (Soy-biodiesel) & 438 & - & - \\
\hline & \multirow{2}{*}{$1500 \mathrm{~W}$} & diesel & 848 & - & - \\
\hline & & B100 (Soy-biodiesel) & 458 & - & - \\
\hline \multirow{4}{*}{$\begin{array}{l}\text { 4-Cylinder direct- } \\
\text { injection diesel } \\
\text { engine }^{9}\end{array}$} & \multirow{2}{*}{$1800 \mathrm{rpm} 0.20 \mathrm{Mpa}$} & ultra-low sulfur diesel (ULSD) & - & 79.2 & 17.1 \\
\hline & & biodiesel from waste cooking oil & - & 119.3 & 3.3 \\
\hline & \multirow{2}{*}{$1800 \mathrm{rpm} 0.55 \mathrm{Mpa}$} & ultra-low sulfur diesel (ULSD) & - & 28.2 & 3.3 \\
\hline & & biodiesel from waste cooking oil & - & 35.4 & 1.4 \\
\hline
\end{tabular}


and PHE, while in particulate phase the most abundant were PYR, PHE, and FLU. Concentration profiles showed similarity to a study performed with engine powered with diesel of low sulfur content. ${ }^{22}$ Another similarity observed in this study was that gas phase emissions were higher than PAH emissions associated to PM (Figure 3). ${ }^{22}$

In general, PAH concentration profiles can be used to determine the contribution of the different emissions sources, such as fuel type. For instance, PHE is a marker for heavy vehicle emissions. Diesel vehicles are sources of low molecular weight PAH, while gasoline vehicles are a major source of high molecular weight $\mathrm{PAH} .{ }^{22}$ The presence of NAF and PHE in the combustion of B5 observed in this study was also found in the work of HE et al. ${ }^{34}$ where they found the presence of PAH with 2 and 3 rings for diesel and binary mixture B20.

PAH in the gas phase showed the same profile of PM and BTEX, which have a tendency to decrease when the fuels were stored. The highest PAH concentrations were obtained on the first 15 minutes of engine operation, period characterized by incomplete combustion, while the lowest was measured in 60 minutes (Figure 3a). As expected, emissions from B5 were higher than B100 and B100 Adt, which were similar to those obtained in the gaseous phase (Figure 3b).
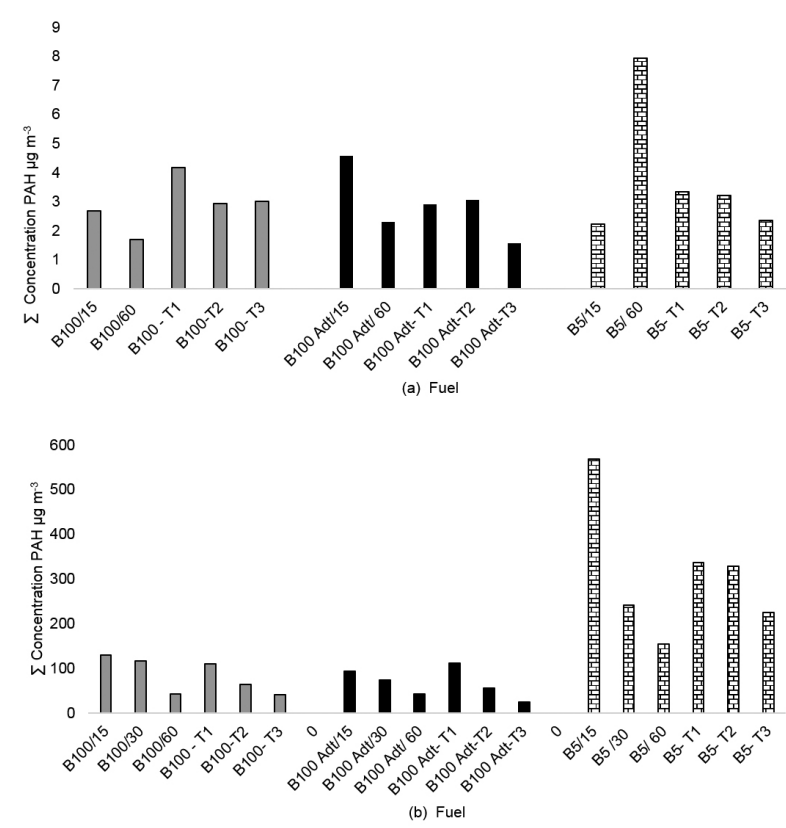

Figure 3. Concentration profiles $\left(\mu \mathrm{g} \mathrm{m}^{-3}\right)$ of $\sum \mathrm{PAH}$ associated to: (a) PM and (b) gas phase. Operation time of the engine was 15, 30, and 60 minutes, and storage periods of T1, T2, and T3 sampled for 30 minutes $(n=1)$.

For PAH associated to PM, the most significant emissions were measured for B5/60 (Figure 3a). For the $\mathrm{PAH}$ associated to gas phase, the most significant emissions were measured for B5/15 (Figure 3b). These results were similar to those found by Karavalakis et al.,${ }^{34}$ where higher PAH emissions occurred in the early stages when the engine is still cold. Furthermore, the quantity of unburned PAH must be higher during the initial part of the cold cycle. ${ }^{34}$ $\mathrm{B} 5$ produced higher levels of PAH during the cold phase than B100 and B100 Adt.

\section{Aldehydes}

In this study, the most abundant aldehydes were formaldehyde and acetaldehyde, as found in previous ones. $^{3-23}$ These aldehydes were in high concentrations in B100 and B100 Adt emissions, except for the sampling period of 60 minutes, characterized by a complete combustion (Figure 4). The oxidative stability of biodiesel is influenced by the unsaturation degree of the alkyl esters and the position of double bonds in the carbon chain. ${ }^{23}$ Under this scenario, soybean biodiesel presents a profile that favors oxidation processes, due to the strong presence of unsaturation in the molecule. The more the degree of unsaturation increases, the more susceptible is the molecule to both thermal and oxidative degradation. ${ }^{35}$ Biofuels do not present significant differences in acetaldehyde concentrations compared to B5, as corroborated by Student's $t$-test (Tables S2 and S3, Supplementary Information). Regarding to formaldehyde, significant differences were obtained for B5/60 vs. B100 Adt/60, B5-T2 vs. B100 Adt-T2, and B5/30 vs. B100/30. Formaldehyde emissions were higher for biofuels. At the storage T1, the biofuels presented formaldehyde concentrations higher than B5 emissions. It can be explained by the oxidation and the auto-oxidation mechanisms, where the hydroperoxides are formed during the primary oxidation stage to decompose and form aldehydes and species with higher molecular weights. ${ }^{15}$ The B100-T1, which did not have BHT antioxidant, should be the first to undergo oxidation. Therefore, the higher concentration of aldehydes in $\mathrm{T} 1$ is explained.

High temperature and exposure to the air are important factors that affect the stability of biodiesel. In urban environments, several studies report that the combustion processes are the main primary source of aldehydes. ${ }^{36}$ Incomplete combustion of oxygenated mixtures in internal combustion engines results in the increase of primary emissions of formaldehyde and acetaldehyde. Photochemical processes associated with the decomposition organic species, e.g., HC, are important secondary sources..$^{23-37}$

The formaldehyde/acetaldehyde ratios were compared with those cited in the literature ${ }^{37}$ and the results were 


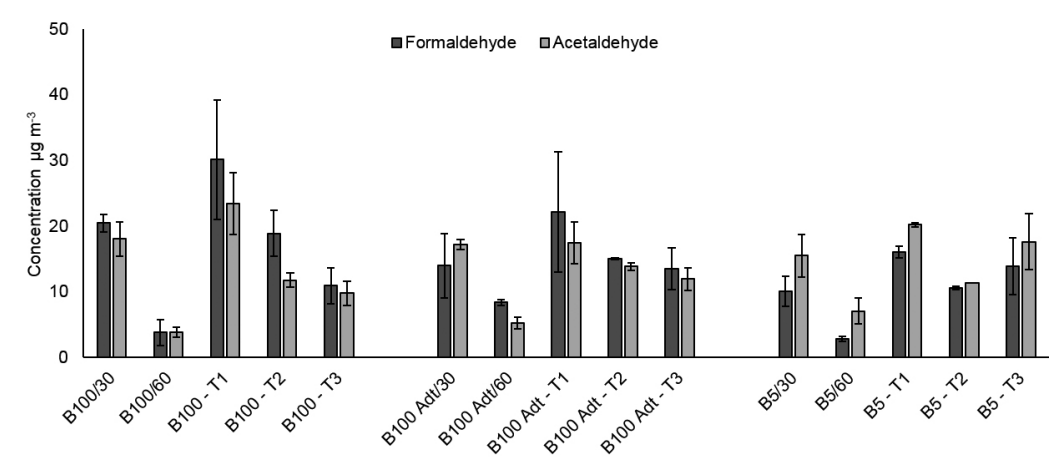

Figure 4. Mean concentration profiles $\left(\mu \mathrm{g} \mathrm{m}^{-3}\right)$ of formaldehyde and acetaldehyde considering operation time of the engine for the fuels B100, B100 Adt, and B5 for the periods of 30 and 60 minutes and storage periods of T1, T2, and T3 for B100, B100 Adt, and B5 sampled for 30 minutes.

consistent. The lowest average rate in this study was 0.7 for B5. This fact may be related to low sunlight, thus it does not present the secondary contribution of formaldehyde originated from photochemical reactions. The highest average ratio was 1.3 for B100 Adt, which may be related to sampling carried out in peak hours of solar radiation. Alvim et al. ${ }^{38}$ reported ratios ranging from 0.7 to 1.7 . According to Student's $t$-test results, no significant differences for these pollutants emissions were observed comparing B100 and B100 Adt. However, comparing the biofuels to B5, there were differences in formaldehyde emissions at 60 minutes (Tables S1, S2, and S3, Supplementary Information).

\section{Metals}

Following the same parameters of the metals associated to the PM, the metal concentration profiles for B100, B100 Adt, and B5 fuels were determined by ICP-MS. The most abundant metals in biofuels were $\mathrm{Fe}, \mathrm{K}$, and $\mathrm{Na}$, while in fossil fuel the major metals were $\mathrm{Al}, \mathrm{Cu}$, $\mathrm{Ca}$, and $\mathrm{Zn}$ (Figure 5). Regarding trace metals, $\mathrm{Ni}$ and $\mathrm{Cr}$ presented higher concentrations for $\mathrm{B} 100, \mathrm{~Pb}$ and $\mathrm{Mg}$ for B5. Zn can be transferred during storage and transport and $\mathrm{Cu}$ is associated to the refining process ${ }^{39}$ The origin of other metals such as $\mathrm{Al}, \mathrm{Pb}$, and $\mathrm{Mg}$ may be related to engines and turbines wear. ${ }^{40}$ Elements such as $\mathrm{Al}, \mathrm{Ca}, \mathrm{Mn}$ may be purposely added as additives to improve specific characteristics of the fuel. ${ }^{41}$ Metals can also be incorporated into fuels and biofuels during the production process due to the presence of these elements in the refining, distillation, transport, and storage equipment.

The metal profiles associated to the PM were determined and evaluated according to the sampling time and the storage period. Mean concentration profiles, in $\mu \mathrm{g}$ $\mathrm{m}^{-3}$, of the main metals of the biofuels B100 and B100 Adt are shown in Figure 6.

According to the Figure 6, the most abundant metals found in B100 and B100 Adt emissions were the same (Fe, $\mathrm{Ca}, \mathrm{K}$, and $\mathrm{Na}$ ) found in the biofuels before the combustion. This fact corroborates with studies which claim metals in low concentration may reach the environment through combustion processes. ${ }^{39}$

Regarding to B5, PM was rich in $\mathrm{Ca}, \mathrm{Na}$, and $\mathrm{Zn}$. Among these metals, $\mathrm{Ca}$ and $\mathrm{Zn}$ were also abundant in the fuel. Studies report that the engine operational conditions can also influence metal emissions, since the engine at low loads can lead to an incomplete combustion or emit unburned fuels. That is the main reason for the high concentrations of metals, when the fuel itself is the major source. ${ }^{16}$

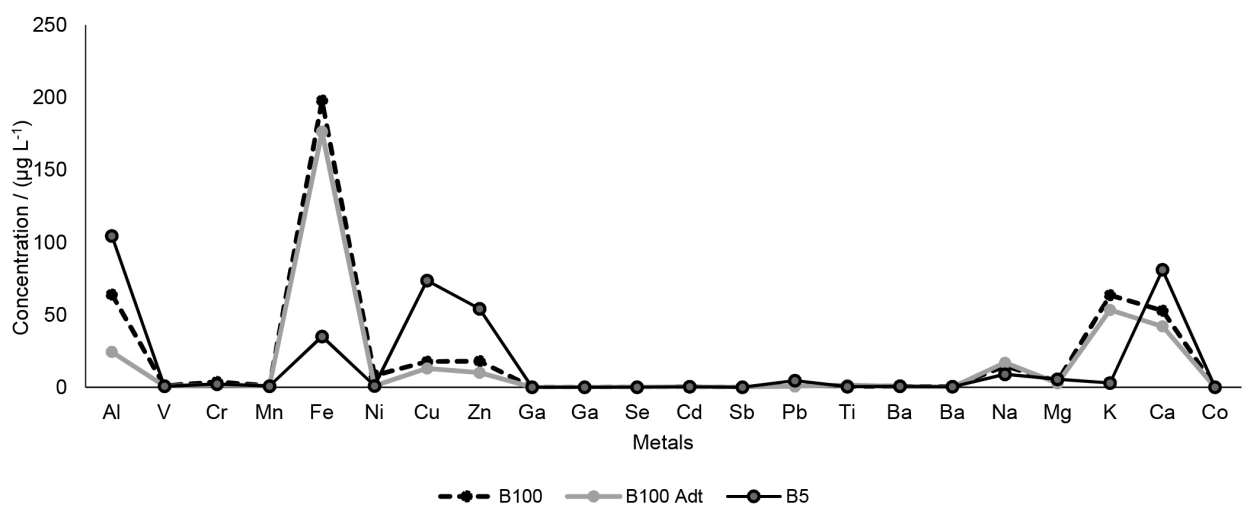

Figure 5. Concentration profiles of the metals in biofuels B100, B100 Adt, and blends B5 ( $\mathrm{n}=1)$. 

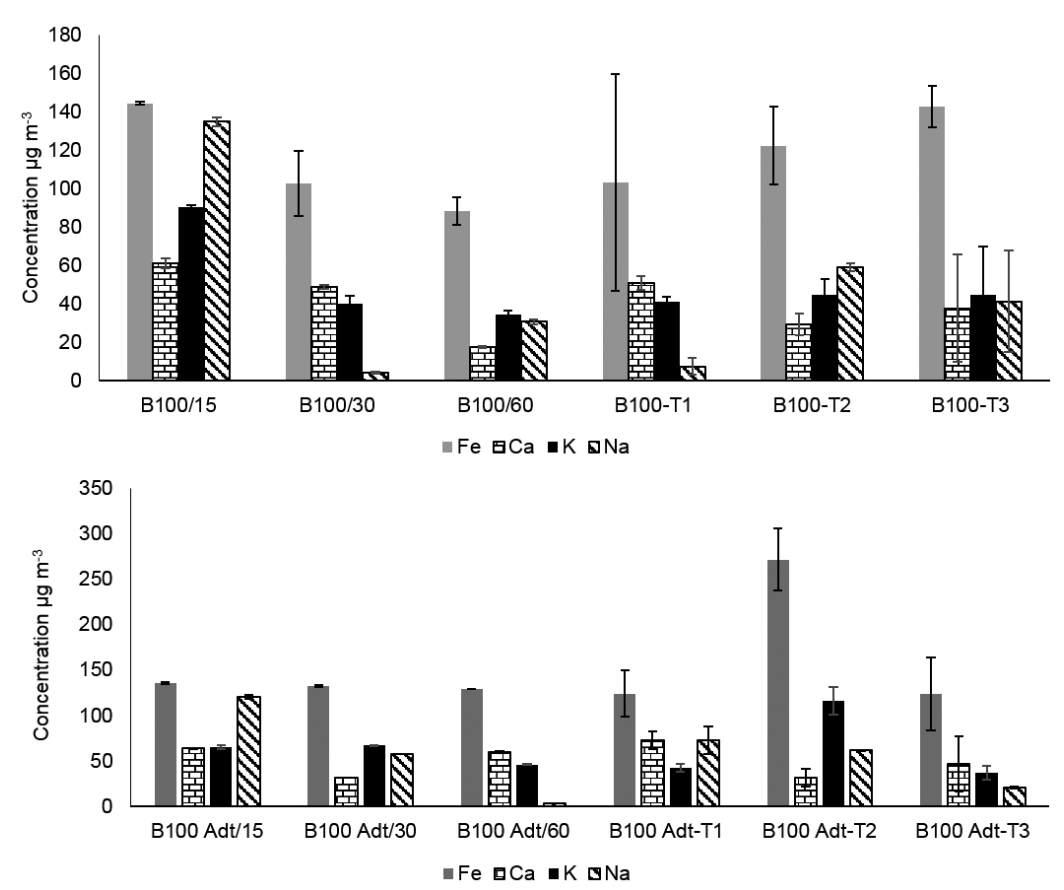

Figure 6. Mean concentration profiles $\left(\mu \mathrm{g} \mathrm{m}^{-3}\right)$ of the main metals associated to PM from biofuels B100 and B100 Adt, considering operation time of the engine at 15,30, and 60 minutes and storage periods of $\mathrm{T} 1, \mathrm{~T} 2$, and $\mathrm{T} 3$ sampled at the time of 30 minutes.

\section{Temperature and relative humidity}

During the burning of the fuels, the relative humidity inside the chamber was 31.9 to $36.2 \%$ for biofuels and 34 to $34.9 \%$ for B5. The temperature was slightly lower in the initial 15 minutes of engine operation for all fuels (Figure S1, Supplementary Information). This factor can influence the profile of pollutants concentrations. ${ }^{9}$

\section{Conclusion}

The viability profile of the use of biodiesel in diesel cycle engines without any modification was evaluated. Although most studies report PM emission reduction with the use of biodiesel, these concentration may be higher for biodiesel as shown in this study. The particles emissions from biodiesel compared to diesel may increase in low temperature engine operation. More oxygenated molecules can reduce particulate emissions when using biodiesel, but engine type, oilseed origin, biofuels physico-chemical characteristics, and engine operation conditions could also influence in the emissions. The hydrocarbons reduction with the use of both pure biodiesel and additivated biodiesel is evident, since only B5 presented xylenes and aliphatic hydrocarbons. Metals emissions, such as $\mathrm{Fe}, \mathrm{Ca}, \mathrm{K}$ and $\mathrm{Na}$, are associated with the fuel and biofuel origins and production processes.

In spite of the limited number of data, it can be inferred that the impact of B100, B100 Adt emissions regarding organic pollutants were smaller than those caused by fossil diesel. In this context, the emissions from fossil diesel by diesel cycle engines were one of the main contributors to environmental degradation due to the large amount of pollutants emitted, including HC, BTEX, and PAH, which may cause damage to human health and the environment. Finally, this study corroborates with verified results obtained in other studies that used renewable fuels such as biodiesel.

\section{Supplementary Information}

Supplementary information (Table S1, S2, and S3: Student's $t$-test comparing the averages of pollutants PM, BTEX and aldehydes between B100, B100 Adt, and B5 considering operation time of the engine at 15,30 , and 60 minutes and storage periods T1, T2, and T3 sampling at 30 minutes. Figure S1: Average results for temperature and relative humidity of B100. B100 Adt and B5 in periods of 15,30 , and 60 minutes) is available free of charge at http:// jbcs.sbq.org.br as PDF file.

\section{Acknowledgments}

The authors are grateful to the Foundation for the Support of Research in Rio de Janeiro State (FAPERJ), National Council for Technological and Scientific Development (CNPq), and Brazilian Federal Agency for Support and Evaluation of Graduate Education 
(PROCAD-CAPES) for financial support for the research. In addition, the authors thank to the staff of the Department of Chemistry of the Federal University of Paraíba.

\section{References}

1. Lobo, I. P.; Ferreira, S. L. C.; Cruz, R. S; Quim. Nova 2009, $32,1596$.

2. Guarieiro, L. L. N.; de Souza, A. F.; Torres, E. A.; de Andrade, J. B.; Atmos. Environ. 2009, 43, 2754

3. Tavares, F. V. F.; Barreto, A. A.; Dutra, E. G.; Jacomino, V. M. F.; Eng. Sanit. Ambient. 2010, 15, 315.

4. Xue, J.; Grift, T. E.; Hansen, A. C.; Renewable Sustainable Energy Rev. 2011, 15, 1098.

5. Shahabuddin, M.; Liaquat, A. M.; Masjuki, H. H.; Kalam, M. A.; Mofijur, M.; Renewable Sustainable Energy Rev. 2013, 21, 623

6. Karavalakis, G.; Stournas, S.; Bakeas, E.; Atmos. Environ. 2009, 43, 1745.

7. Haas, M. J.; Scott, K. M.; Alleman, T. L.; McCormick, R.; Energy Fuels 2001, 1207.

8. Kado, N. Y.; Kuzmicky, P. A.; Bioassay Analyses of Particulate Matter from a Diesel Bus Engine Using Various Biodiesel Feedstock Fuels. Final Report. Report 3 in a Series of 6; National Renewable Energy Laboratory, U.S. Department of Energy, Office of Scientific and Technical Information: Oak Ridge, TN, USA, 2003. Available at: http://www.nrel.gov/docs/ fy03osti/31463.pdf, accessed in July 2016.

9. Di, Y.; Cheung, C. S.; Huang, Z.; Sci. Total Environ. 2009, 407, 835 .

10. Lin, Y.-f.; Wu, Y.-P. G.; Chang, C.-T.; Fuel 2007, 86, 1772.

11. Hansen, K. F.; Jensen, M. G.; SAE Technical Paper 1997, 971689

12. Munack, A.; Schröder, O.; Krahl, J.; Bünger, J.; Agricultural Engineering International: CIGR Journal 2001, III, manuscript EE 01001.

13. Monyem, A.; Van Gerpen, J. H.; Biomass Bioenergy 2001, 20, 317.

14. Bakeas, E.; Karavalakis, G.; Fontaras, G.; Stournas, S.; Fuel 2011, 90, 3200.

15. Lapuerta, M.; Armas, O.; Rodriguez-Fernandez, J.; Prog. Energy Combust. Sci. 2008, 34, 198.

16. Agarwal, A. K.; Gupta, T.; Kothari, A.; Renewable Sustainable Energy Rev. 2011, 15, 3278.

17. Gomes, S.; Gauer, M. A.; Schirmer, W. N.; De Souza, S. N. M.; Ambiência 2013, 9, 335.

18. Ferreira, S. L.; Santos, A. M. D.; Souza, G. R. D.; Polito, W. L.; Módolo, D. L.; Quim. Nova 2008, 31, 539.
19. Zou, L.; Atkinson, S.; Environ. Technol. 2003, 24, 1253.

20. He, C.; Ge, Y.; Tan, J.; You, K.; Han, X.; Wang, J.; Fuel 2010, 89, 2040

21. Gioda, A.; de Aquino Neto, F. R.; Indoor Built Environ. 2002, $11,302$.

22. Corrêa, S. M.; Arbilla, G.; Atmos. Environ. 2006, 40, 6821.

23. Corrêa, S. M.; Arbilla, G.; Atmos. Environ. 2008, 42, 769.

24. EPA - 8270D; Gas Chromatography/Mass Spectrometry for Semi Volatile Organics Capillary Column Technique; US Environmental Protection Agency, 2007.

25. Gioda, A.; Amaral, B. S.; Monteiro, I. L. G.; Saint'Pierre, T. D.; J. Environ. Monit. 2011, 13, 2134.

26. Yamane, K.; Kawasaki, K.; Sone, K.; Hara, T.; Int. J. Engine Res. 2007, 8, 307.

27. Turrio-Baldassarri, L.; Battistelli, C. L.; Conti, L.; Crebelli, R.; De Berardis, B.; Iamiceli, A. L.; Iannaccone, S.; Sci. Total Environ. 2004, 327, 147.

28. Boian, C.; Brumatti, M. M.; Fornaro, A.; Rev. Hipótese 2015, 1,15 .

29. Tsai, J. H.; Chen, S. J.; Huang, K. L.; Lin, Y. C.; Lee, W. J.; Lin, C. C.; Lin, W. Y.; J. Hazard. Mater. 2010, 179, 237.

30. Magalhães, D.; Bruns, R. E.; Vasconcellos, P. C.; Quim. Nova 2007, 30, 577.

31. Barabas, I.; Todoruț, A.; Băldean, D.; Fuel 2010, 89, 3827.

32. Wang, W. G.; Lyons, D. W.; Clark, N. N.; Gautam, M.; Norton, P. M.; Environ. Sci. Technol. 2000, 34, 933.

33. Shahir, V. K.; Jawahar, C. P.; Suresh, P. R.; Renewable Sustainable Energy Rev. 2015, 45, 686.

34. Karavalakis, G.; Deves, G.; Fontaras, G.; Stournas, S.; Samaras, Z.; Bakeas, E.; Fuel 2010, 89, 3876.

35. Borsato, D.; Maia, E. C. R.; Dall'Antonia, L. H.; da Silva, H. C.; Pereira, J. L.; Quim. Nova 2012, 35, 733.

36. Cheung, C. S.; Zhu, L.; Huang, Z.; Atmos. Environ. 2009, 43, 4865.

37. Nomi, S. N.; Sakugawa, H.; Takeda, K.; Solci, M. C.; Semina: Cienc. Exatas Tecnol. 2010, 31, 23.

38. Alvim, D. S.; Gatti, L. V.; Santos, M. H. D.; Yamazaki, A.; Eng. Sanit. Ambient. 2011, 16, 189.

39. Saint'Pierre, T. D.; Dias, L. F.; Maia, S. M.; Curtius, A. J.; Spectrochim. Acta, Part B 2004, 59, 551.

40. Burguera, J. L.; Avila-Gómez, R. M.; Burguera, M.; de Salager, R. A.; Salager, J. L.; Bracho, C. L.; de Pena, Y. P.; Talanta 2003, 61,353 .

41. Korn, M. D. G. A.; dos Santos, D. S. S.; Welz, B.; Vale, M. G. R.; Teixeira, A. P.; Lima, D. C.; Ferreira, S. L. C.; Talanta 2007, 73,1 . 